\title{
An Atypical Presentation of Severe Dissecting Aortic Aneurysm: A Case Report and Literature Review
}

\author{
Ahmed Mowafy ${ }^{1}$, Payal Rath ${ }^{1}$, Ahmed Eladly ${ }^{2}$, Ahmed Omran ${ }^{2}$ \\ 1. Internal Medicine, Rutgers/Trinitas Regional Medical Center, Elizabeth, USA 2. Clinical Research, University of \\ Louisville, Louisville, USA
}

Corresponding author: Ahmed Mowafy, ahmedmowafy.m.d@outlook.com

\begin{abstract}
A 55-year-old male patient with no past medical history presents to the ED to complain of exertional dyspnea and bilateral lower limb swelling. The patient was diagnosed with a severe dissecting aortic aneurysm on trans-thoracic echocardiography and later confirmed by a contrast CT aortogram. The patient was immediately started on anti-impulse therapy with labetalol infusion and underwent emergent aortic dissection repair. This case demonstrates an atypical presentation of a life-threatening condition that might have been missed on the initial assessment.
\end{abstract}

Review began 05/31/2021 Review ended 06/05/2021 Published 06/18/2021

\section{() Copyright 2021}

Mowafy et al. This is an open access article distributed under the terms of the Creative Commons Attribution License CC-BY 4.0., which permits unrestricted use, distribution, and reproduction in any medium, provided the original author and source are credited.
Categories: Cardiac/Thoracic/Vascular Surgery, Cardiology, Internal Medicine Keywords: asymptomatic aortic dissection, aortic dissection diagnosis, aortic dissection management, literature review of disease, atypical presentation

\section{Introduction}

Aortic dissection is an uncommon (2.6-3.5 per 100,000 person-years), but morbid condition, with mortality rates, reported around 20-30\% [1]. The most common risk factors for dissecting aortic aneurysms are uncontrolled hypertension, atherosclerosis, dyslipidemia, and smoking. Less common risk factors include connective tissue disorders like Marfan syndrome, vasculitis, and traumatic causes [2]. Patients are usually 60-80-year-old men (mean 63y). Women typically present later (mean 67y). It typically presents severely and catastrophically, with chest pain and hemodynamic instability being the most common onset symptoms. This case report demonstrates an atypical presentation that closely mimics that of decompensated congestive heart failure. However, the patient was ultimately diagnosed with a severe thoracic aortic dissection secondary to uncontrolled hypertension, with a paradoxically preserved cardiac efficiency.

\section{Case Presentation}

A 55-year-old male patient with no past medical history presented to the ED with complaints of shortness of breath, with exertion, then later at rest, progressive bilateral leg swelling, and generalized fatigue for the preceding two weeks. He endorsed orthopnea and nocturnal paroxysmal dyspnea but denied headache, dizziness, syncope, chest pain, cough, abdominal pain, nausea, vomiting, diarrhoea, constipation, claudication, varicose veins, and limb numbness.

On presentation, the patient was afebrile, body temperature 98.7, tachycardic and hypertensive, heart rate 103 bpm, BP 169/76 mmHg, respiration rate (RR) 20/min, O2 saturation 98\% breathing ambient air. Physical examination revealed faint bilateral pulmonary crackles over the lower lung fields, in addition to a 3/6 harsh diastolic murmur auscultated over the left sternal border and apex, with a non-displaced point of maximal apical impulse. It was also noted that the patient had moderate to severe bilateral lower limb pitting edema up to the knees. The remainder of his examination was non-pertinent.

His labs revealed Hgb $10.7 \mathrm{gm} / \mathrm{dL}$ (12-16 gm/dL), WBC 8.1(4.8-10.8), serum sodium 138 mMol/L (136-146 $\mathrm{mMol} / \mathrm{L})$, potassium $4.1 \mathrm{mMol} / \mathrm{L}$ (3.6-5.1 mMol/L), chloride $107 \mathrm{mMol} / \mathrm{L}$ (101-111 mMol/L), bicarbonate 21 $\mathrm{mMol} / \mathrm{L}(22-32 \mathrm{mMol} / \mathrm{L})$, creatinine $0.8 \mathrm{mg} / \mathrm{dL}(0.4-1.0 \mathrm{mg} / \mathrm{dL})$, blood urea nitrogen (BUN) $16 \mathrm{mg} / \mathrm{dL}(8-20$ $\mathrm{mg} / \mathrm{dL})$, albumin $2.7 \mathrm{gm} / \mathrm{dL}$ (3.5-4.8 gm/dL), total Bilirubin $1.6 \mathrm{mg} / \mathrm{dL}(0.4-2.0 \mathrm{mg} / \mathrm{dL})$, alanine aminotransferase (ALT) $48 \mathrm{U} / \mathrm{L}$ (17-63 U/L), aspartate aminotransferase (AST) $31 \mathrm{U} / \mathrm{L}$ (15-41 U/L).

His brain natriuretic peptide (BNP) was $15 \mathrm{pg} / \mathrm{ml}(<100 \mathrm{pg} / \mathrm{ml})$. His lipid panel revealed a cholesterol of 160 $\mathrm{mg} / \mathrm{dL}$ (120-200 mg/dL), high-density lipoproteins (HDL) $28 \mathrm{mg} / \mathrm{dL}$ (29-71 mg/dL), low-density lipoproteins (LDL) $115 \mathrm{mg} / \mathrm{dL}(<100 \mathrm{mg} / \mathrm{dL})$, and triacyl glycerides $87 \mathrm{mg} / \mathrm{dL}(40-199 \mathrm{mg} / \mathrm{dL})$. His initial Troponin I was $0.04 \mathrm{ng} / \mathrm{ml}(<0.5 \mathrm{ng} / \mathrm{ml})$.

A trans-thoracic echocardiogram was obtained, and it revealed the patient's left ventricular ejection fraction to be 50-55\%, with hypertensive cardiomyopathy and a globally decreased left ventricular systolic function. 


\section{Cureus}

It also revealed a mild mitral valve regurgitant jet, and a mildly dilated pulmonary artery and an elevated pulmonary artery systolic pressure. But the most important finding was a moderate to severe aortic regurgitation, with Type I dissection of the ascending and descending aorta, and the aortic arch (figures 1-2).

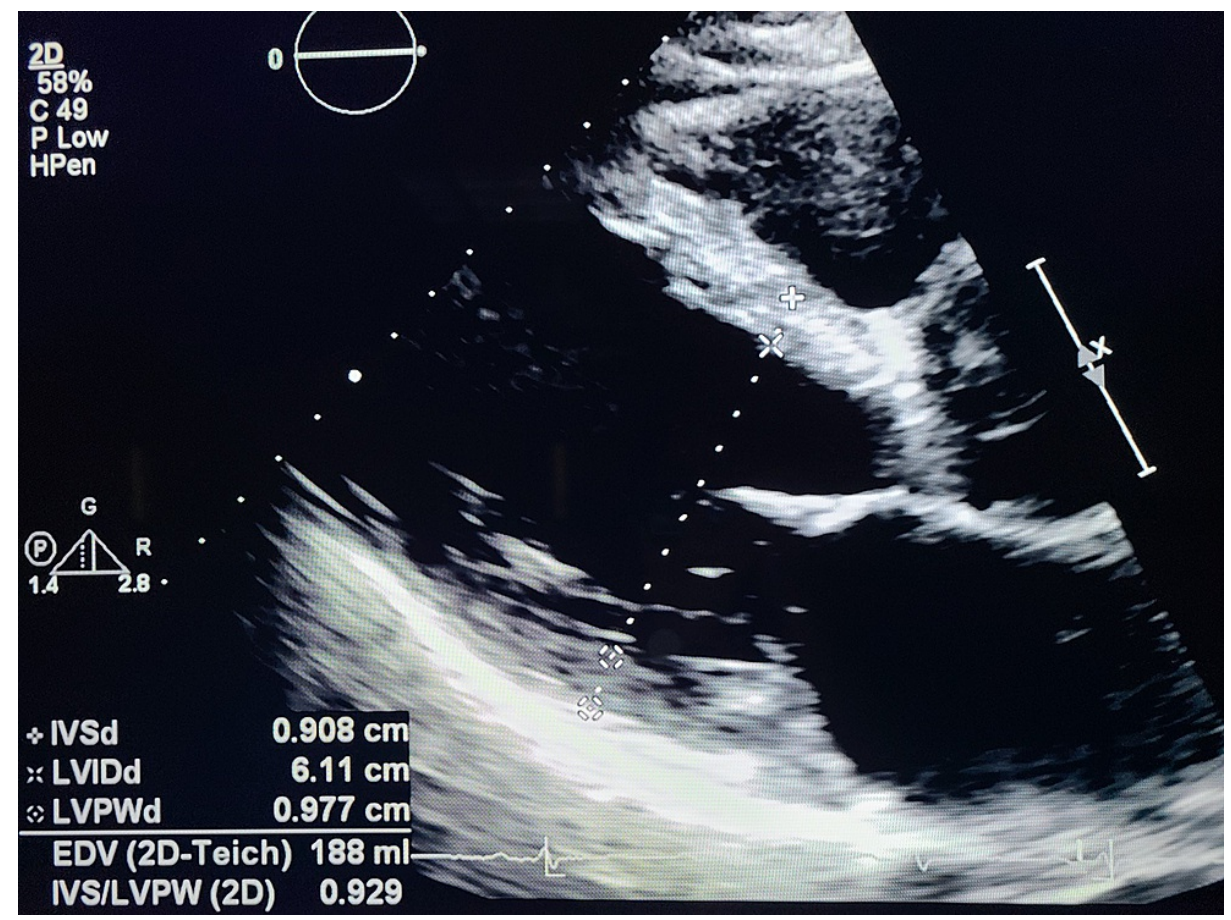

FIGURE 1: Echocardiography demonstrating aortic regurgitation

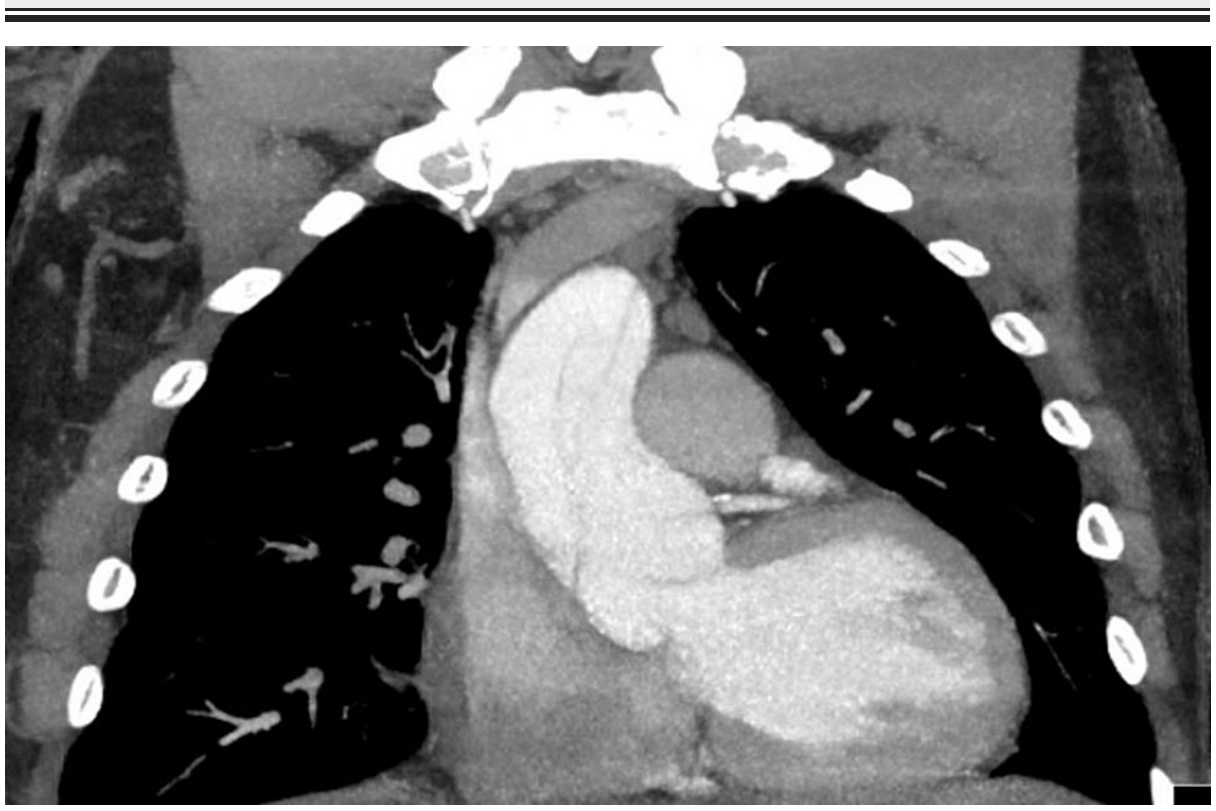

FIGURE 2: CT angiogram of the chest demonstrating aortic double lumen

Upon discovering these findings, a contrast CT angiogram of the chest and an aortogram was obtained, which in turn revealed severe aortic dissection extending from the aortic root all the way down to the iliac bifurcation (figures 3-6). 


\section{Cureus}

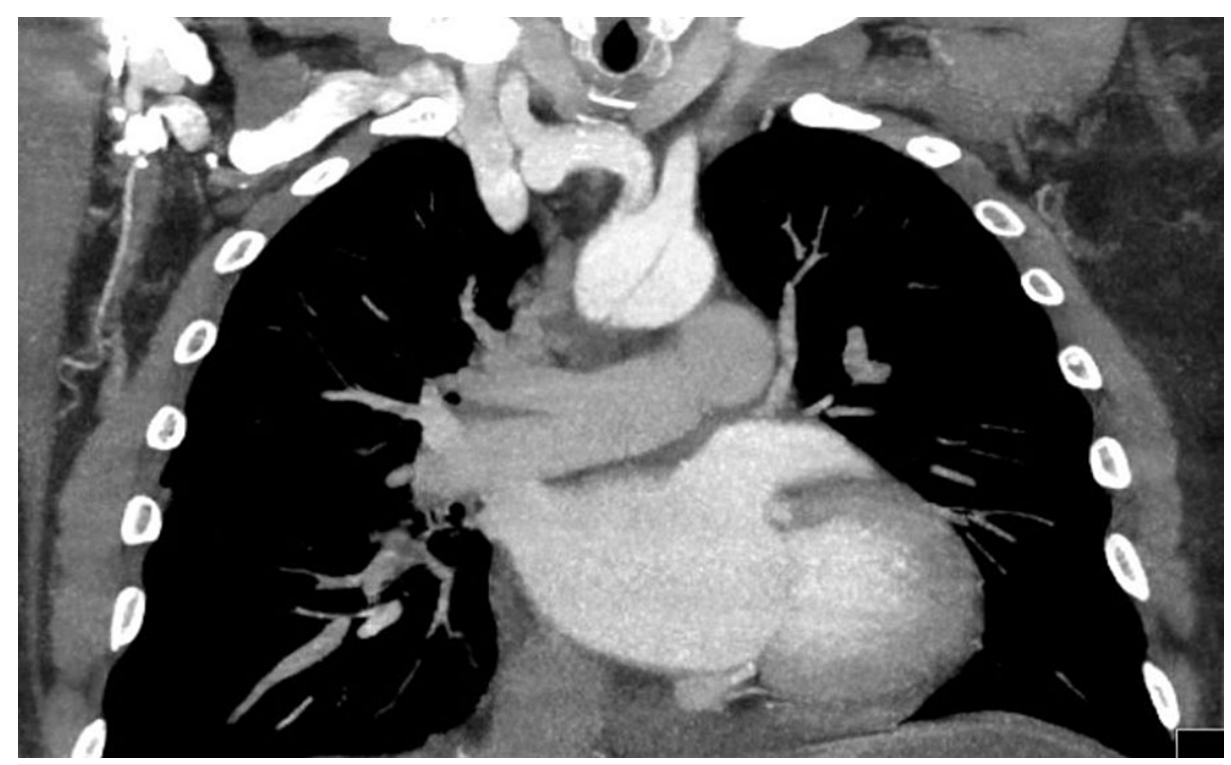

FIGURE 3: CT angiogram demonstrating aortic arch double lumen

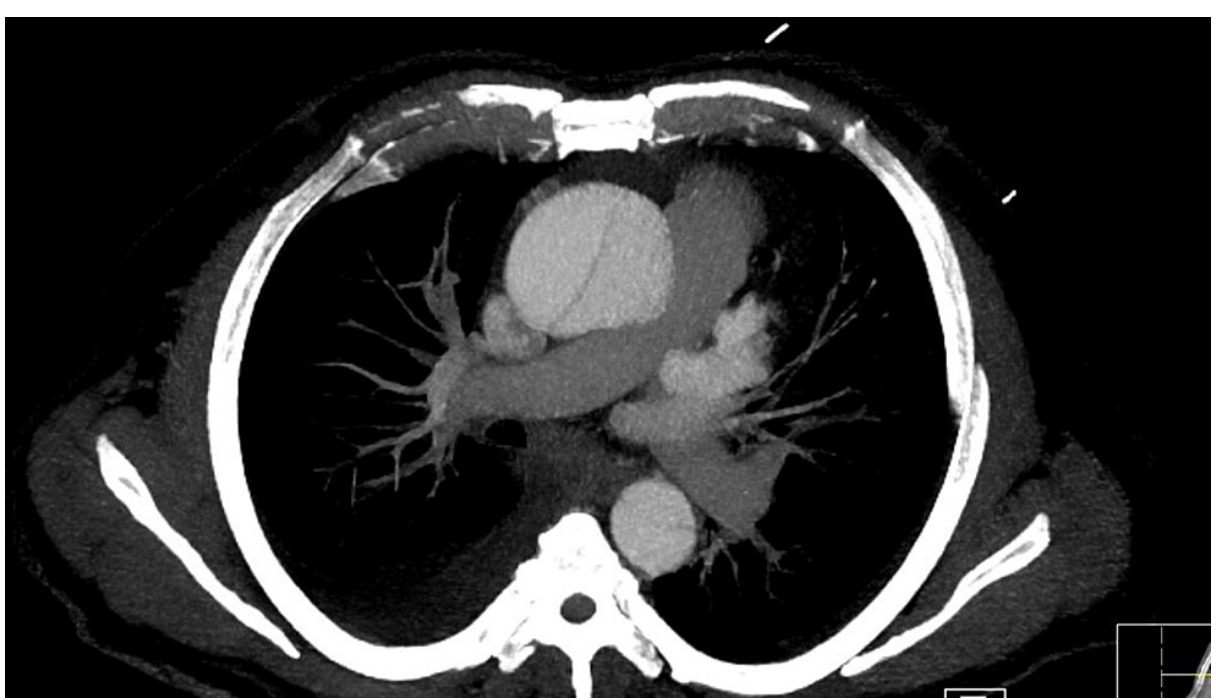

FIGURE 4: CT angiogram demonstrating descending aorta double lumen 


\section{Cureus}

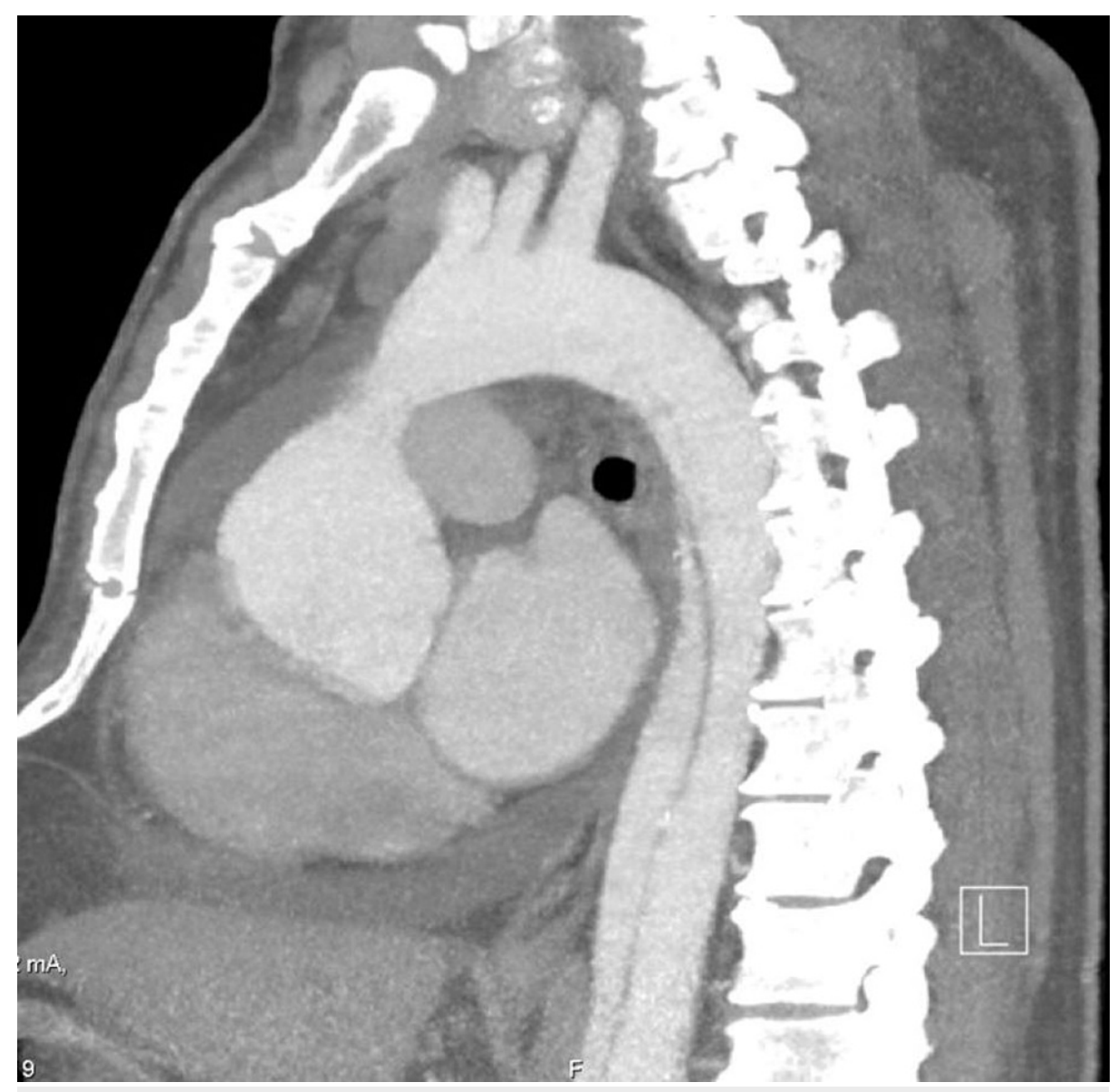

FIGURE 5: CT angiogram of the chest demonstrating the descending aorta double lumen 


\section{Cureus}

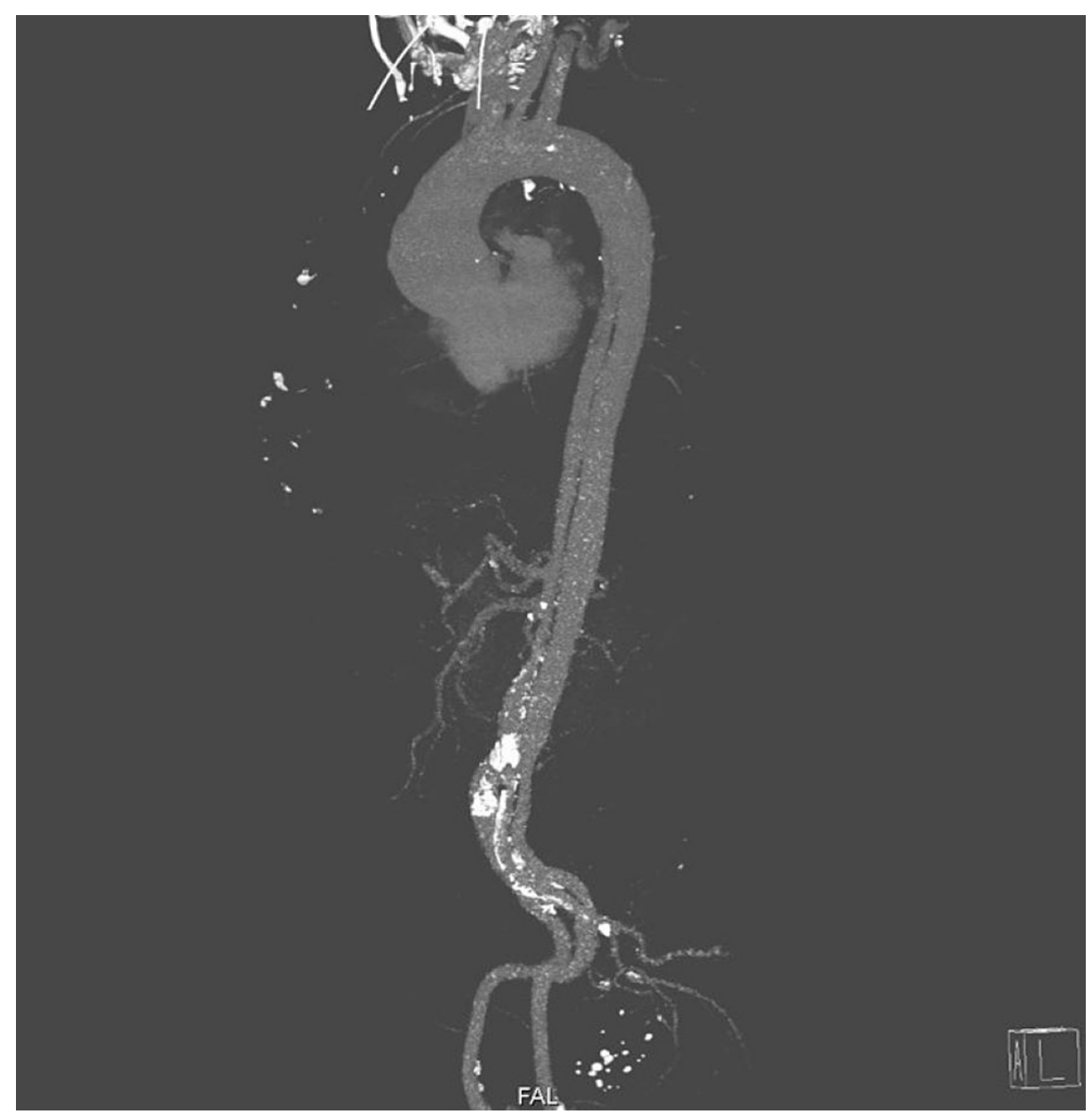

\section{FIGURE 6: An aortogram demonstrating the extent of the dissection from the aortic root to the iliac bifurcation}

The patient was immediately transferred to the Intensive Care Unit, and started on furosemide for volume status optimization, and started on a labetalol drip for decreasing the blood pressure and ventricular contraction velocity to alleviate the shearing force on the aortic wall (anti-impulse therapy), with a target heart rate of less than $60 \mathrm{bpm}$ and blood pressure less than 120/89 $\mathrm{mmHg}$.

After stabilization, the patient was transferred to another facility and underwent a successful aneurysm surgical repair and aortic valve replacement. He was discharged on continuous anti-impulse therapy for outpatient follow up.

\section{Discussion}

As stated before, aortic dissection is a life-threatening condition that usually presents acutely and with catastrophic outcomes. Mortality rates vary according to patients' age, gender, and stage at presentation. However, according to a whole nation study conducted on 153 patients by Melvinsdottir et al., around 17\% died before hospital arrival. In contrast, the risk of death for patients who arrived alive at a hospital was $21.4 \%$ within $24 \mathrm{~h}$ and $45.2 \%$ at 30 days [3]. The study also shows that with proper surgical or medical management, depending on the condition, the 30-day mortality rate improves with every year, and the fiveyear survival rate has been increasing steadily.

Aortic dissection can be classified according to a presentation of "acute" and "chronic", depending on the duration of symptoms before a presentation. Less than two weeks between the onset of symptoms and presentation falls into the acute category, and beyond that window, it is labelled a chronic condition. This classification is of significance given that acute onsets are much more liable to complications related to the extension of the dissection and involvement of major aortic branches like the carotids, left subclavian, or even coronaries.

Perhaps a more relevant classification regarding morbidity and mortality rates would be the Stanford classification. According to this classification, a Type A dissection involves the ascending aorta, and a Type 
B dissection does not. Unfortunately, Type A dissections are almost twice as common as Type B [2]. Moreover, Type A dissection management is generally surgical, while Type B is standardly managed medically.

Mortality in Type A cases managed surgically ranges between $18-22 \%$, depending on postoperative complications. In comparison, mortality among Type A patients managed medically is $57 \%$, a value that naturally explains the inclination to manage Type A surgically. Type B, on the other hand, shows mortality benefit when managed medically, as mortality rates among medically treated patients are around $12 \%$ within the first 30 days, while patient's who are managed with surgical or endovascular intervention experienced a mortality rate of $15-21 \%$ [4]. A study by Pape et al. in 2015 proposes a mortality rate of $30 \%$ in patients with Type B aneurysm who were treated surgically compared to a rate of $10 \%$ who were managed medically [5].

In our case, the most common presenting symptom for a dissecting aneurysm is sharp, severe chest pain, with occasional radiation to the back in $>90 \%$ of patients, while painless dissections account for less than $6.5 \%$ of cases. Signs like hemodynamic instability and pulse and blood pressure disparity between upper limbs, which our patient did not have, present in around $33 \%$ of cases, correlate poorly with mortality and complication rates [2].

Aortic regurgitation is also a common sign in proximal dissections, occurring in $50 \%$ of cases [6]. Acute decompensated congestive heart failure is a known complication of severe aortic dissections. However, it typically coexists with syncope, chest pain, abdominal pain, and malperfusion symptoms to vital organs and distal peripheries [5].

Our patient had acute decompensated heart failure symptoms but none of the other symptoms that usually accompany it. An echocardiography revealed an LVEF of 50-55\%, effectively ruling out reduced ejection fraction heart failure. Furthermore, his lab work did not reveal any organ affection, creatinine, and liver enzymes within normal limits.

The most likely etiology behind the development of our patient's condition is undiagnosed, uncontrolled hypertension. He was hypertensive on presentation and stated that he had never seen a physician in his life before. So our patient falls into the narrow fraction of cases with acute, severe dissecting aortic aneurysm with almost none of the typical presenting symptoms. And especially regarding the severity of the condition and the dissection involving the entire aorta from root to bifurcation, his quality of life before presentation and survival are remarkable.

\section{Conclusions}

Severe aortic dissection is a severe and often life-threatening condition, and clinicians are often comfortable with its diagnosis and management, given how drastically it typically presents. However, in this case, we demonstrate a severe case of aortic dissection that presented with almost none of the typical markers of the condition, especially the severity. We hope this case report would raise the medical community's awareness regarding the rare subtle cases that could be missed or misdiagnosed because of atypical presentations.

\section{Additional Information}

\section{Disclosures}

Human subjects: Consent was obtained or waived by all participants in this study. Conflicts of interest: In compliance with the ICMJE uniform disclosure form, all authors declare the following: Payment/services info: All authors have declared that no financial support was received from any organization for the submitted work. Financial relationships: All authors have declared that they have no financial relationships at present or within the previous three years with any organizations that might have an interest in the submitted work. Other relationships: All authors have declared that there are no other relationships or activities that could appear to have influenced the submitted work.

\section{References}

1. Bickerstaff LK, Pairolero PC, Hollier LH, et al.,: Thoracic aortic aneurysms: a population-based study . Surgery. 1982, 92:1103-8. 10.5555/uri:pii:1003960608290174X

2. Nienaber CA, Eagle KA: Aortic dissection: new frontiers in diagnosis and management: part I: from etiology to diagnostic strategies. Circulation. 2003, 5:628-35. 10.1161/01.CIR.0000087009.16755.E4

3. Melvinsdottir IH, Lund SH, Agnarsson BA, Sigvaldason K, Gudbjartsson T, Geirsson A: The incidence and mortality of acute thoracic aortic dissection: results from a whole nation study. Eur J Cardiothorac Surg. 2016, 50:1111-1117. 10.1093/ejcts/ezw235

4. Evangelista A, Isselbacher EM, Bossone E, et al.,: Insights from the international registry of acute aortic dissection. a 20-Year experience of collaborative clinical research. Circulation. 2018, 24:1846-1860. 10.1161/CIRCULATIONAHA.117.031264

5. Pape LA, Awais M, Woznicki EM, et al.,: Presentation, diagnosis, and outcomes of acute aortic dissection: 17-Year trends from the international registry of acute aortic dissection. J Am Coll Cardiol. 2015, 28:350-8. 10.1016/j.jacc.2015.05.029 


\section{Cureus}

6. Hagan PG, Nienaber CA, Isselbacher EM, et. Al: The international registry of acute aortic dissection (IRAD): new insights into an old disease. JAMA. 2000, 16:897-903. 10.1001/jama.283.7.897 